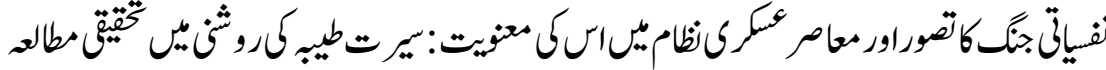 \\ The Concept of Psychological War and Its Meaningfulness in the Contemporary Military System: Study In The Light Of Seerah
}

*Saeed ul Haq Jadoon

PhD. Scholar, Department of Islamic Studies, Abdul Wali Khan University, Mardan, Pakistan.

**Imtiaz Ali

PhD. Scholar, Department of Islamic Studies, Abdul Wali Khan University, Mardan, Pakistan.

\section{VERSION OF RECORD}

Received: 21-Aug-19 Accepted: 12-Nov-19

Online/Print: 31-Dec-19

\begin{abstract}
Nuclear weapon based modern era has many modes of war prevailed, in which a significant and influential one is psychological war. In this regard, the most important is the strategy of war and it is necessary to command over the psyche of enemy. Sometimes, adopting the psychological plan, we get rid of a great war that is why before the war different countries are trying to exert psychological pressure over their enemies. They show many air borne fights and assaults through media, so that to overwhelm through it. Psychological war is legal right of every one at International and Religious Laws. In modern war theories, Psychological war is the best way for success. Psychological war is not a new invention but the holy Prophet $(S A W)$, a sample showed us. He (SAW) put the dead bodies of enemies in the wells. He (SAW) burnt the fire during Fath-e-Makkah, cut the trees in Ghazwa Banu Nazir. From Seerah we conclude that Psychological war is very important for the martial system and inversely effect the enemy. In this article, Author(s) mentioned the concept of psychological war and its impact in the light of Seerah.

Keywords: Psychological, War, Military, Pressure, Seerah, Enemies, Propaganda. To Cite this Article:

Jadoon, S. ul H., \& Ali, I. (2019). URDU: نفسياتى جنك كا تصوراور معاصر عسكرى نظام ميى اس كى معنويت: سيرت طيبه كى روشنى ميى تحقيقى مطالعه. İQĀN, 2(03), 55-67.
\end{abstract}




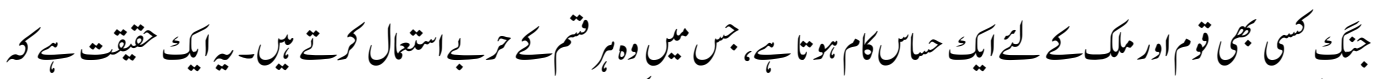

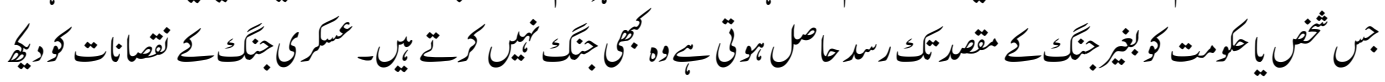

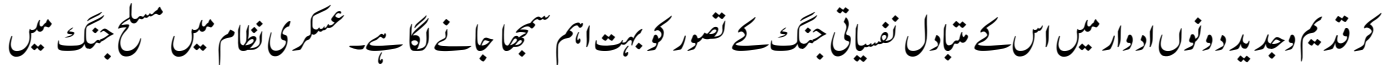

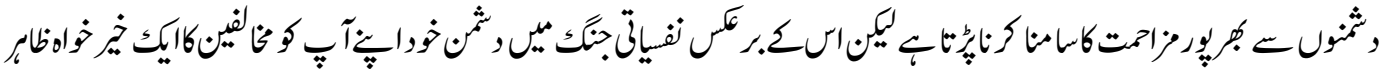

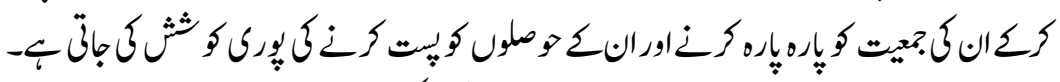

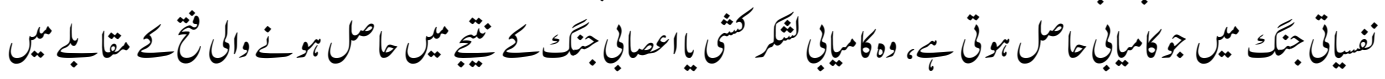

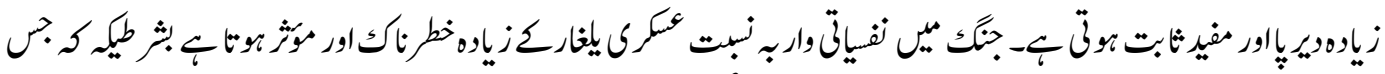

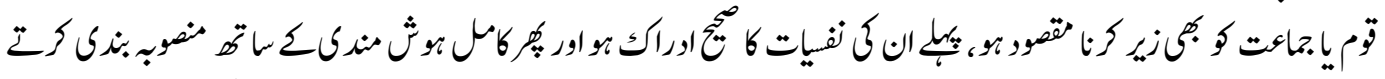

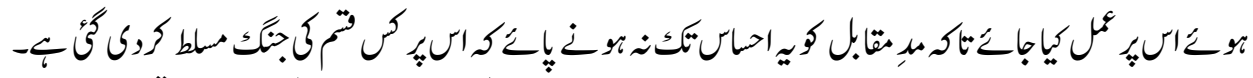

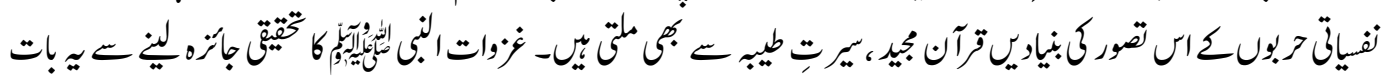

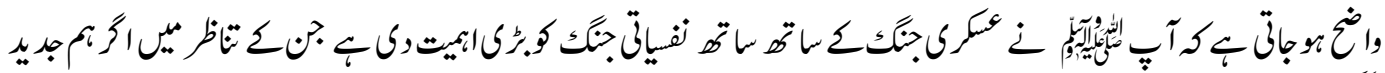

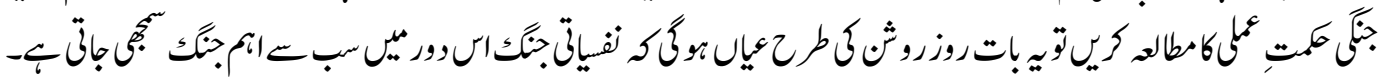

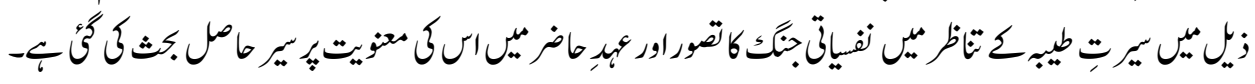

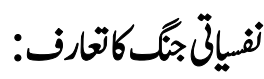

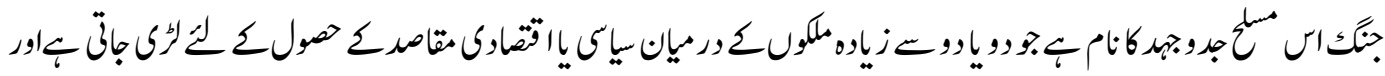

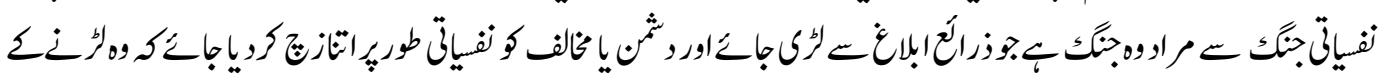

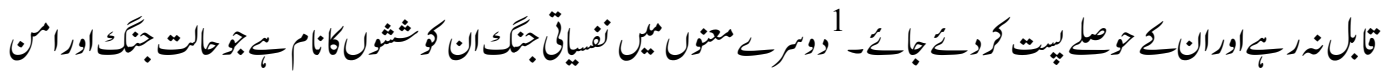

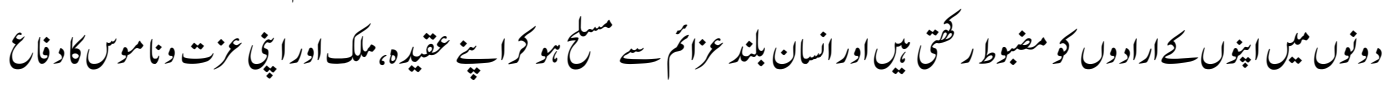

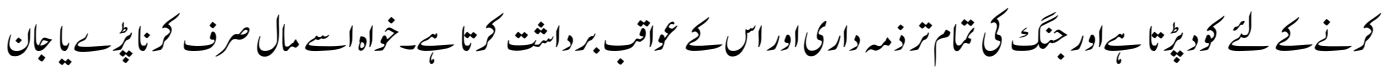

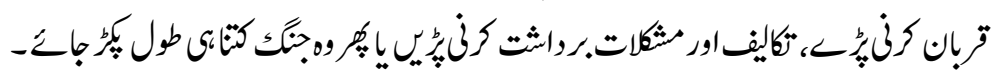

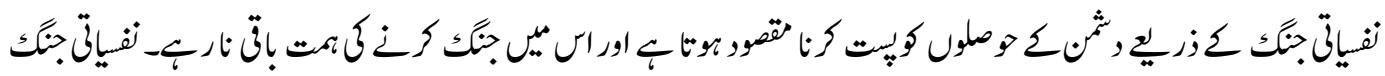

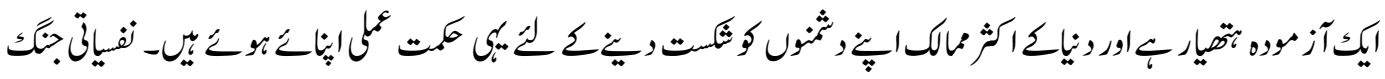




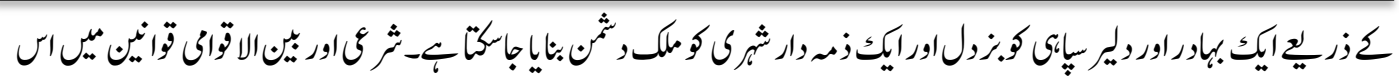

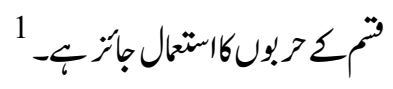

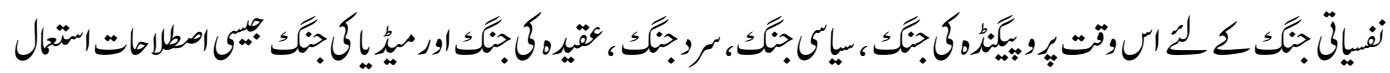

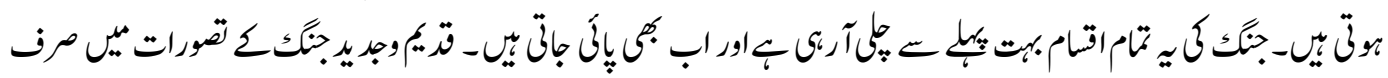

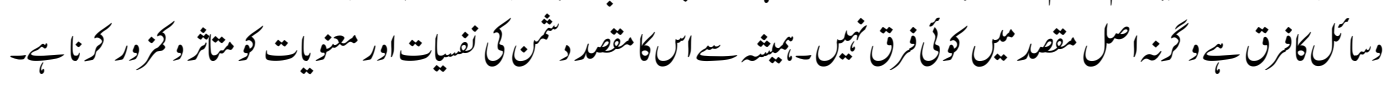

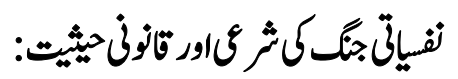

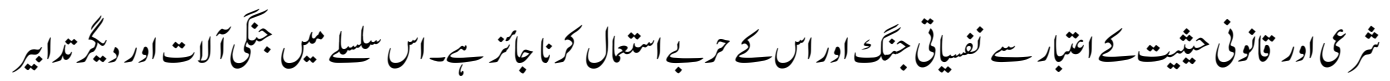

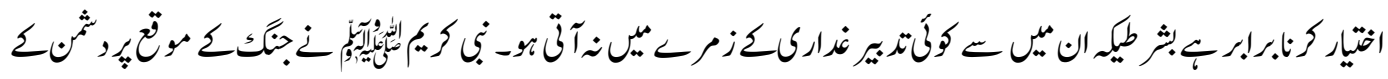

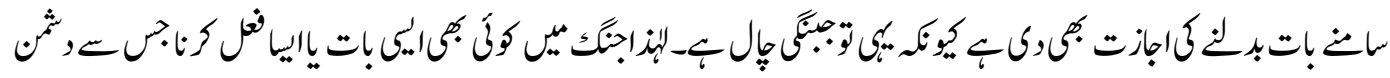

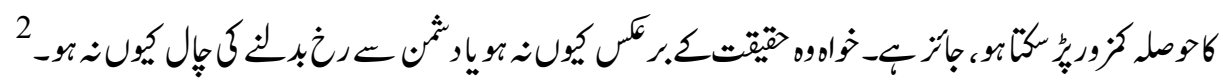

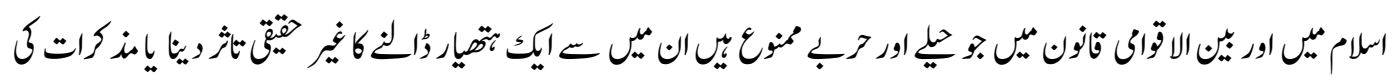

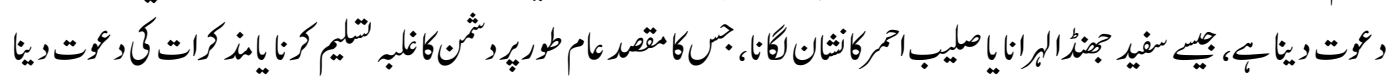

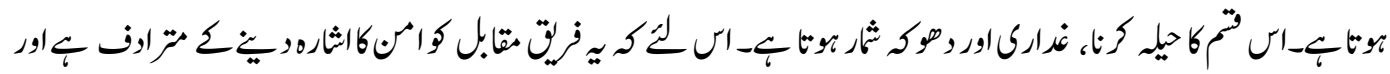

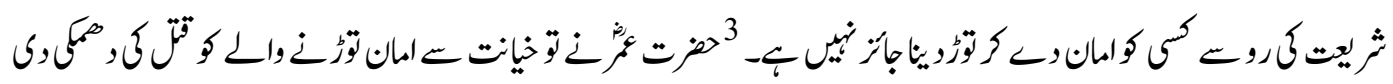

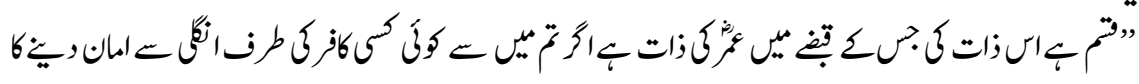

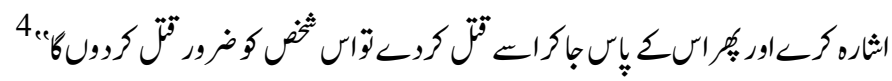

نق

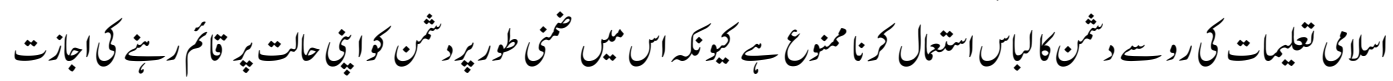

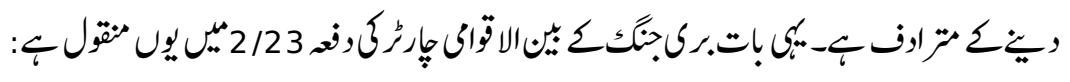

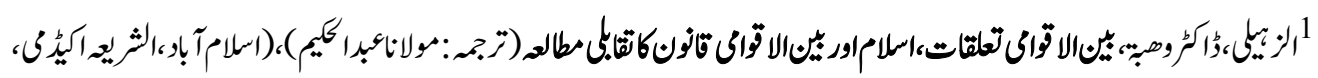

$\angle 9: 0.0 \% \cdot 10$

"اليضاً

1:

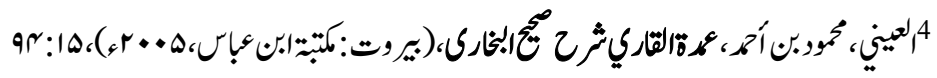




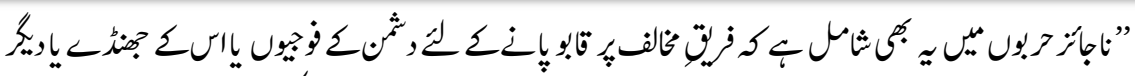

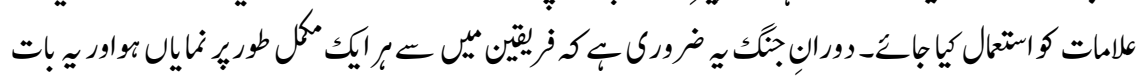

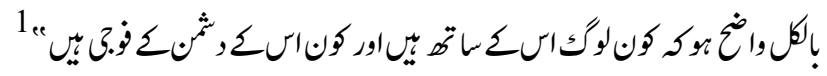

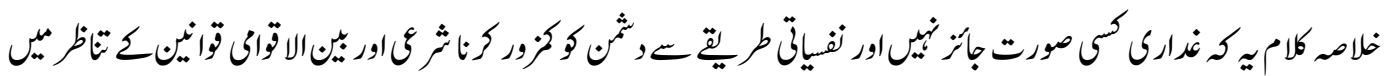
جائزب

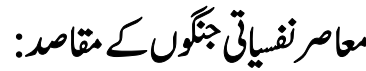

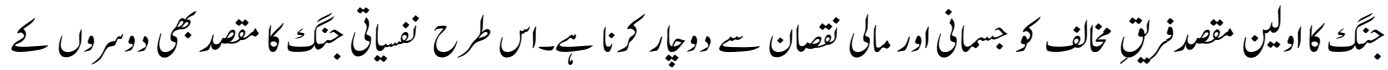

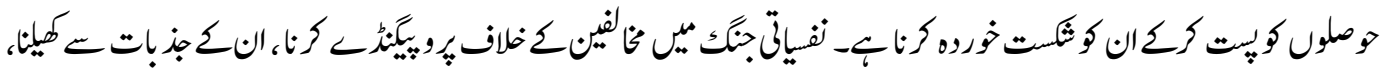

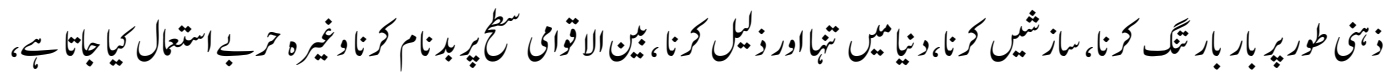

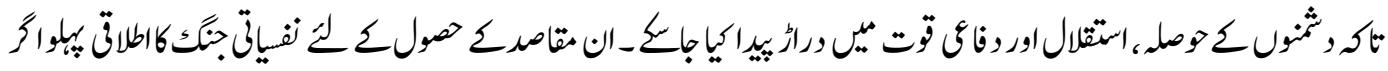

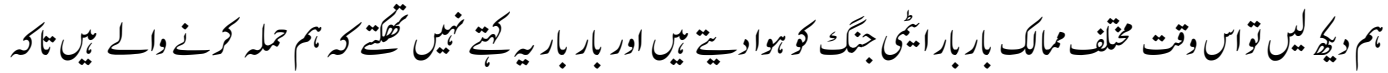

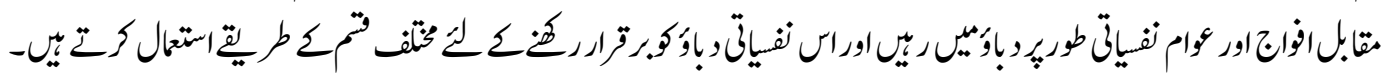

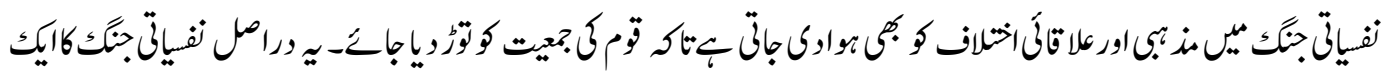

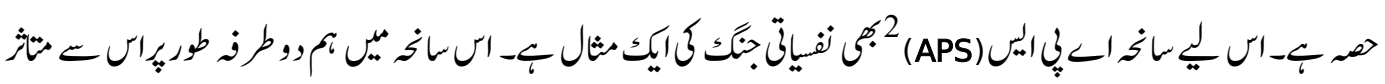

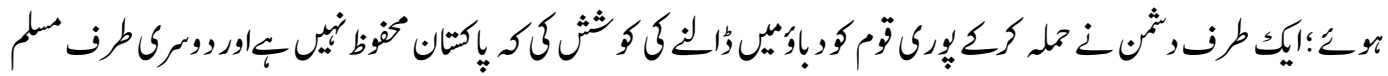

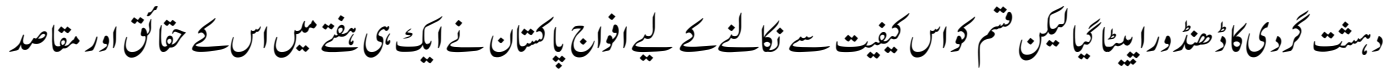

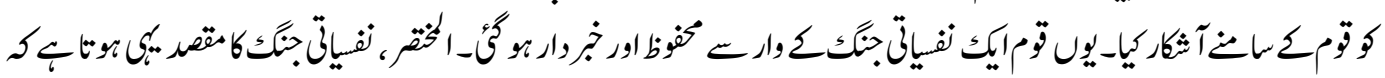

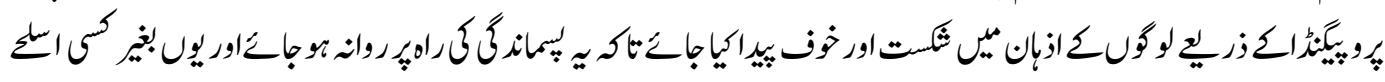

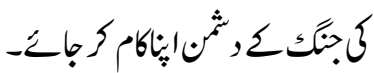

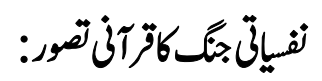

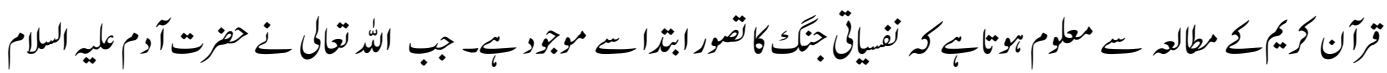

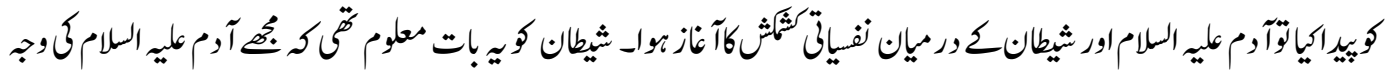

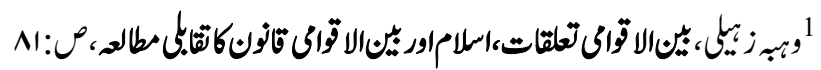
APS ${ }^{2}$ 


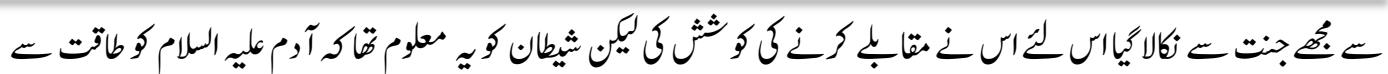

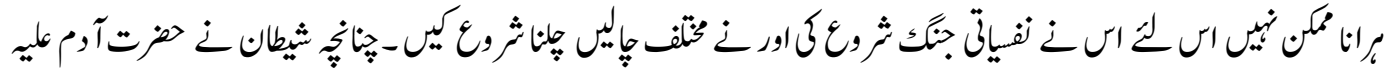

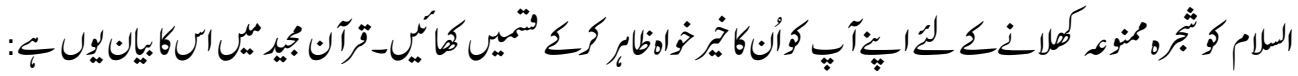

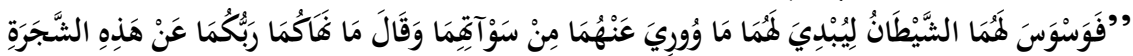

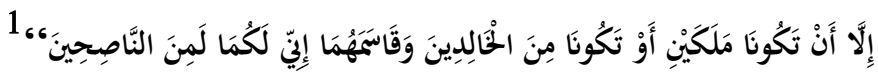

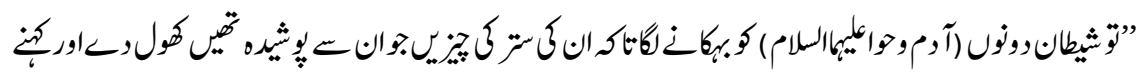

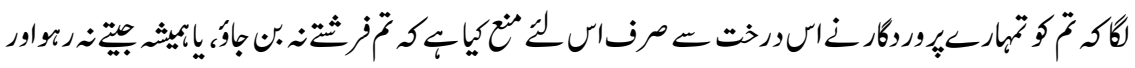

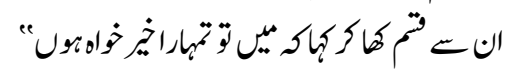

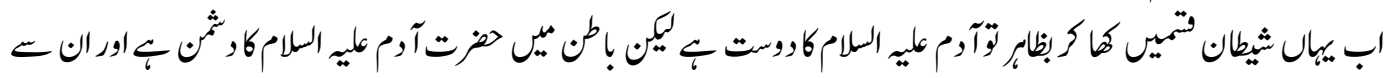

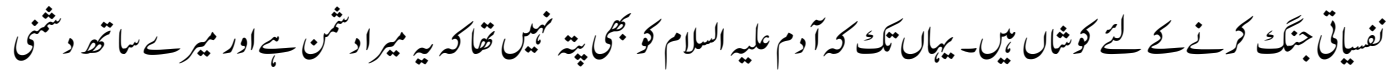

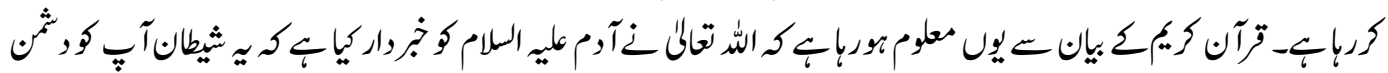

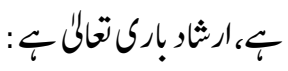

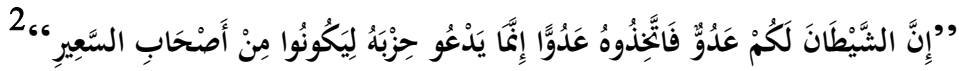

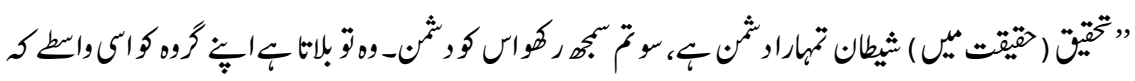

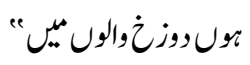

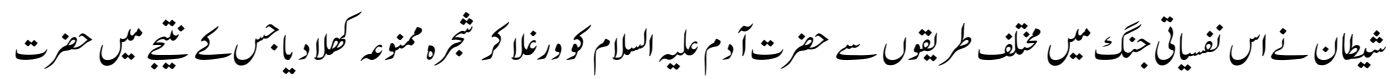

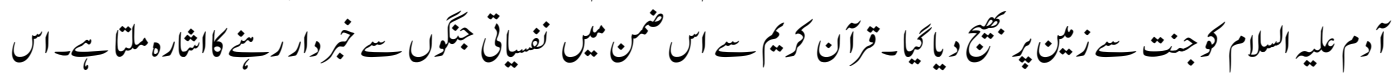

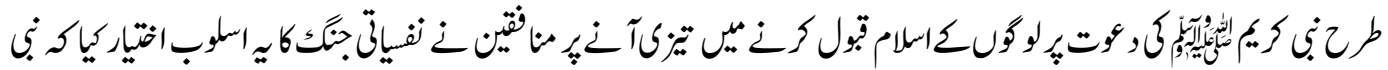

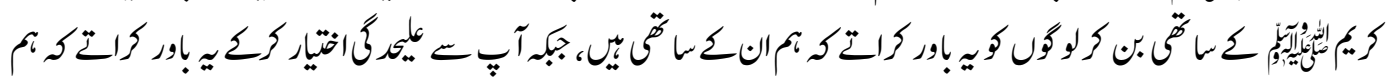

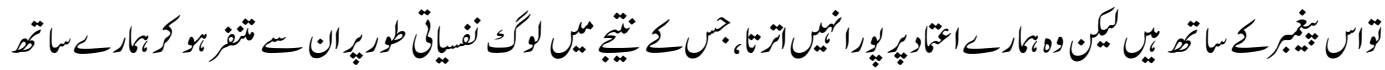

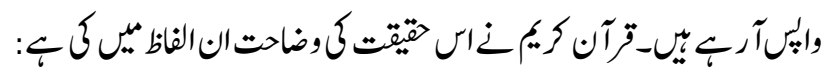

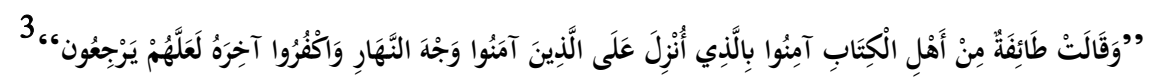

$$
\begin{aligned}
& \text { 1واف :•rار } \\
& \text { 4: } b^{2} \\
& \text { 3r: }
\end{aligned}
$$




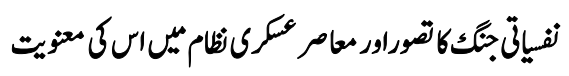

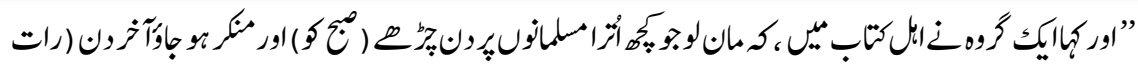

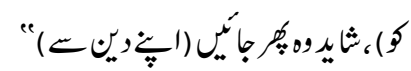

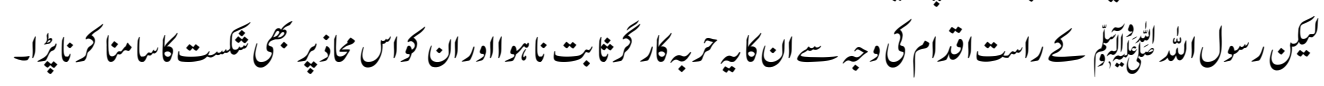

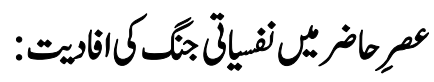

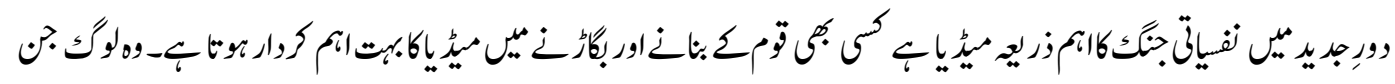

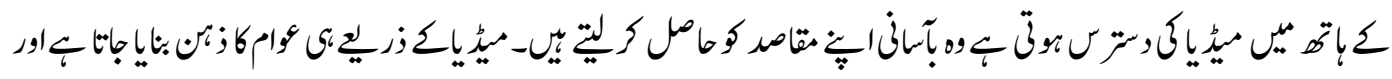

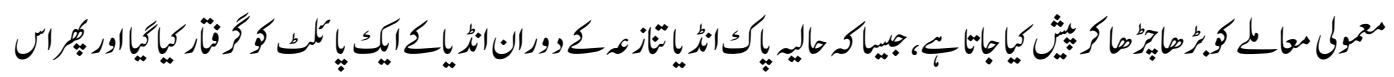

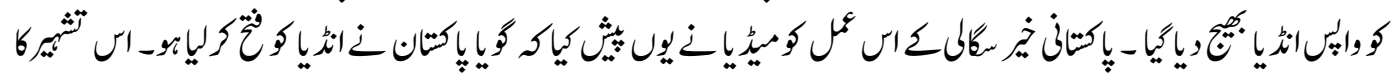

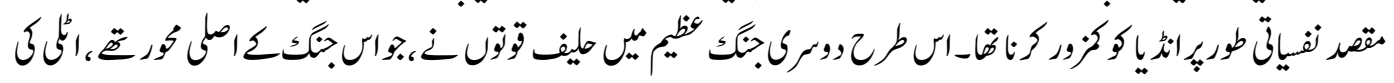

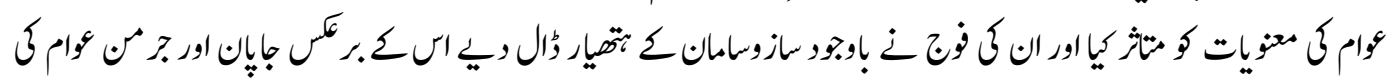

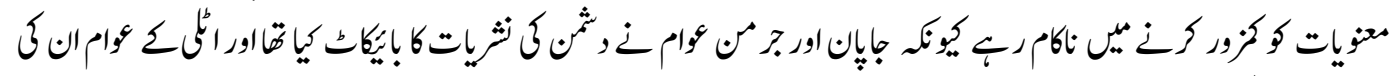

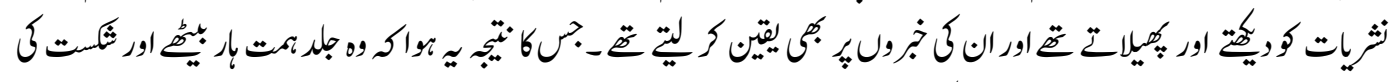

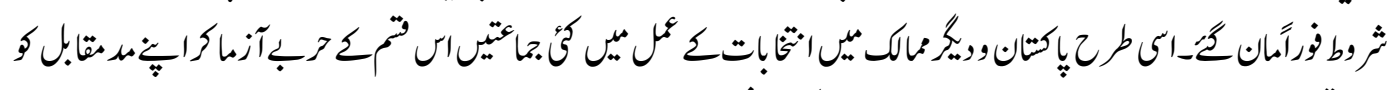

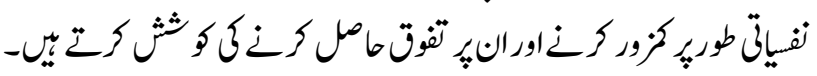

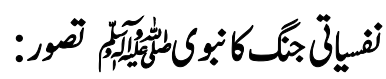

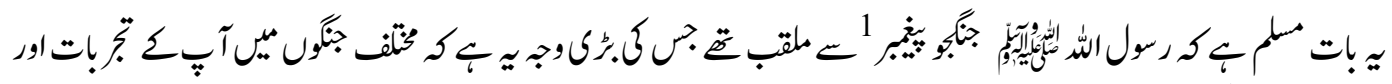

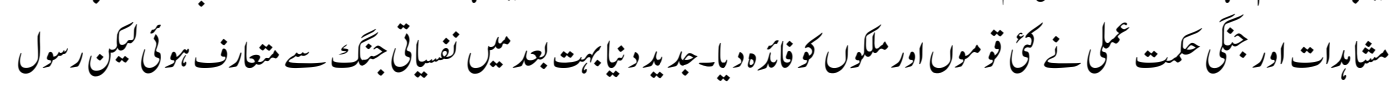
الش

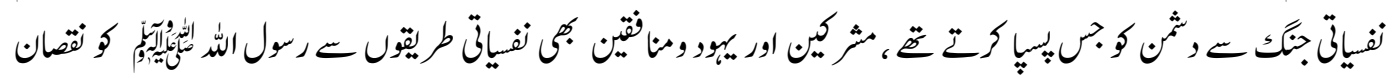

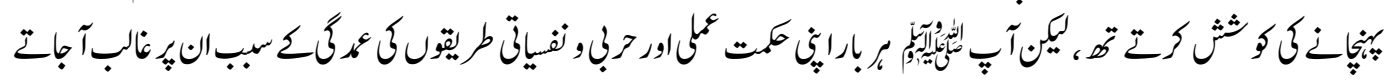

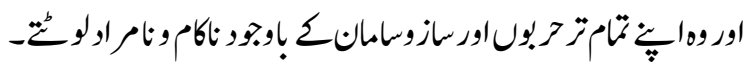

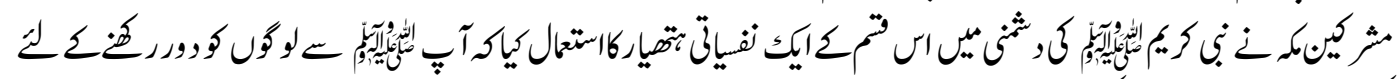
管

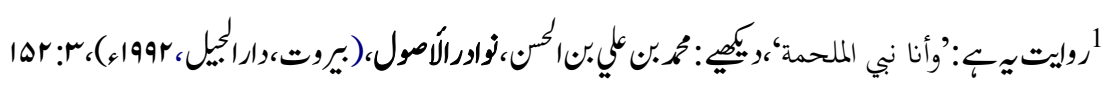

60

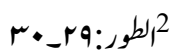




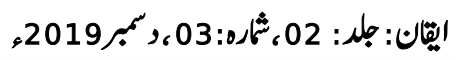

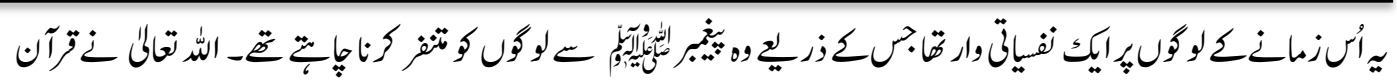

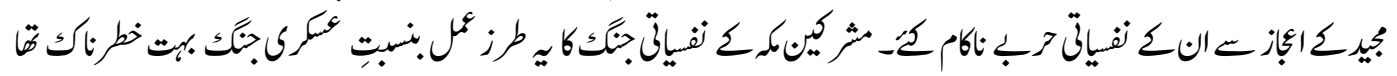

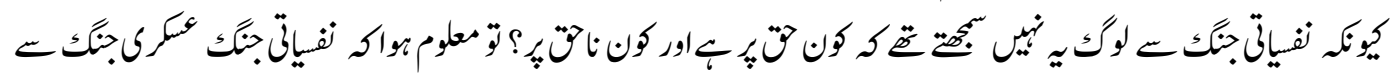

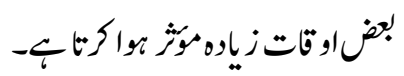

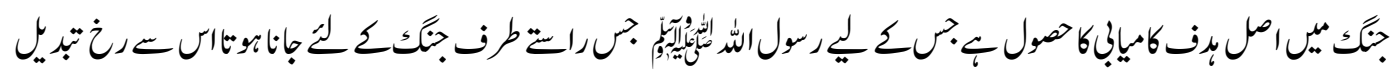
ك ك, كورى

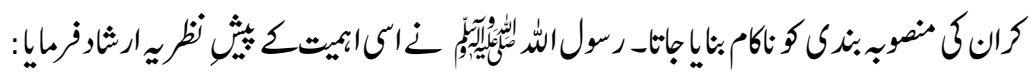

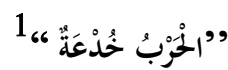

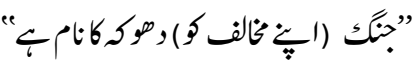

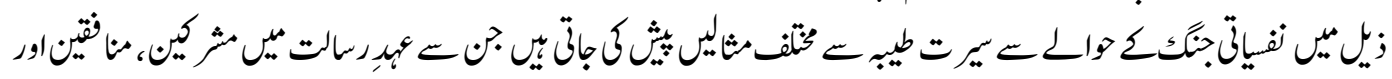

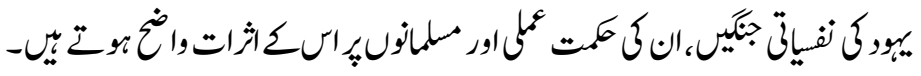

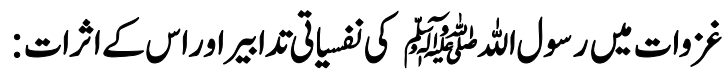

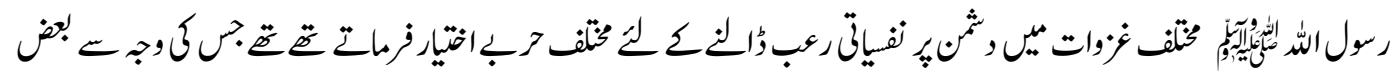

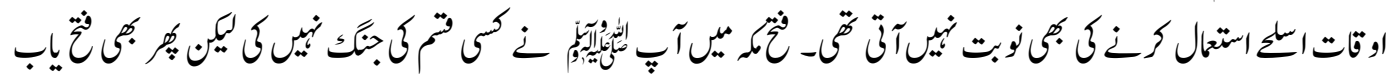

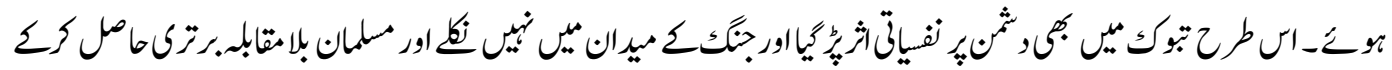

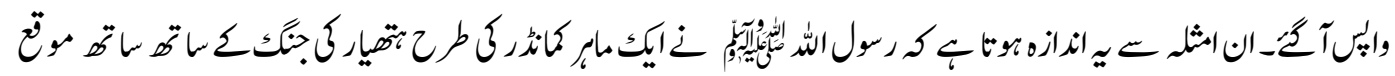

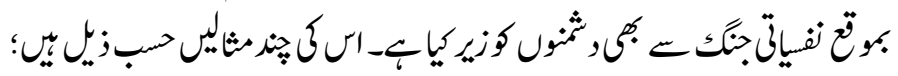

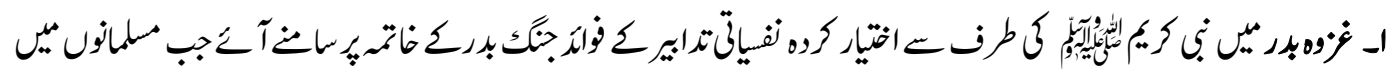

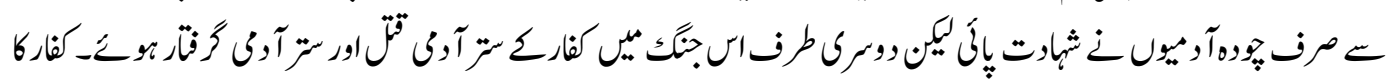

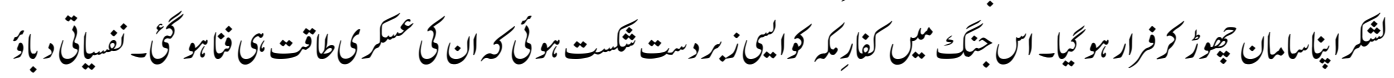

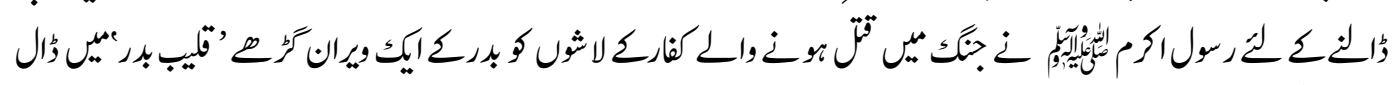

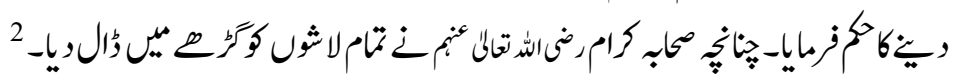

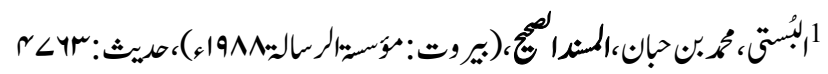

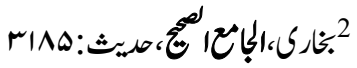

61 


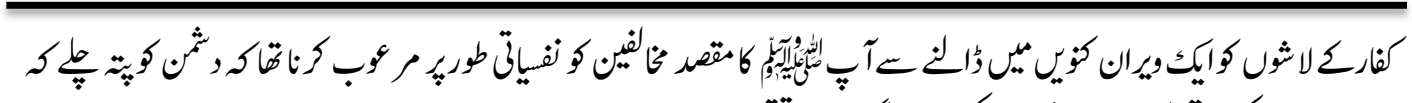

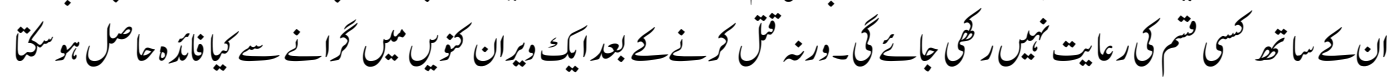

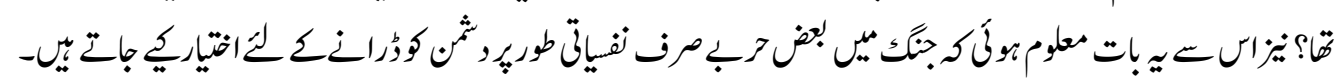

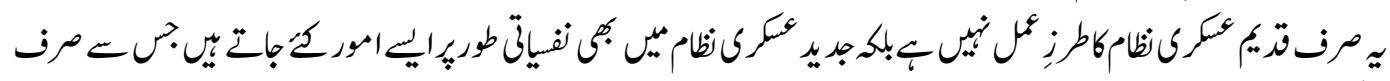

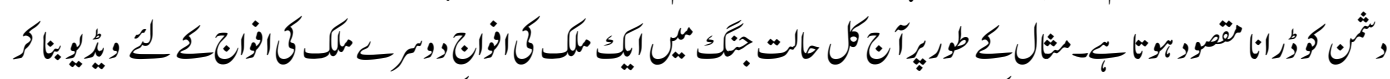

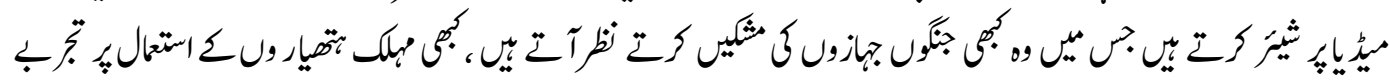

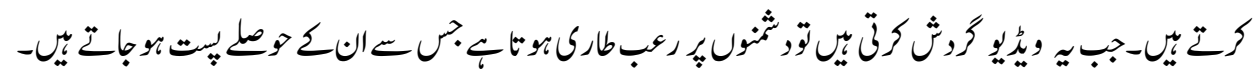

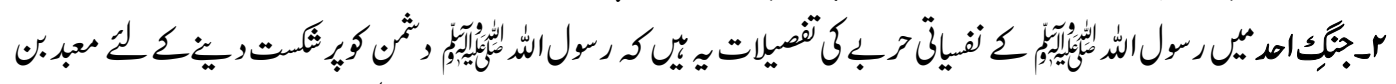

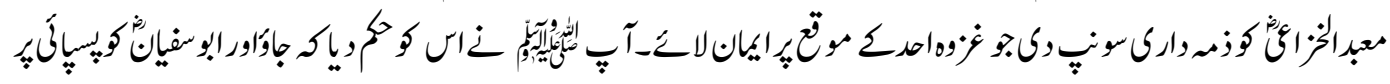

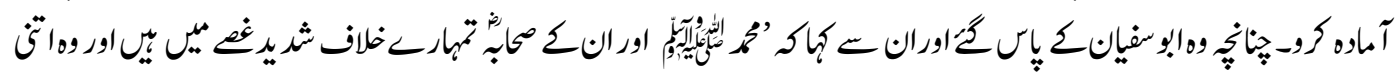

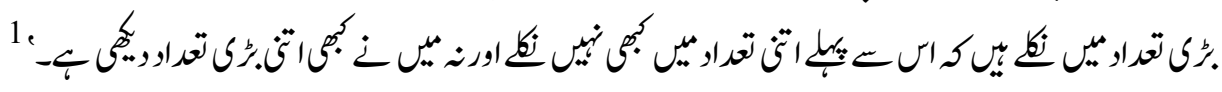

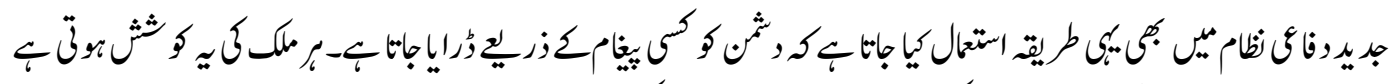

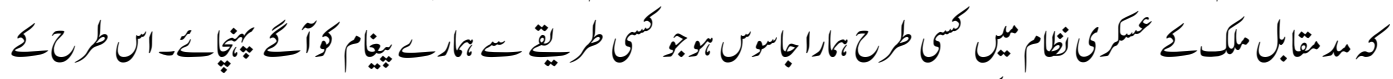

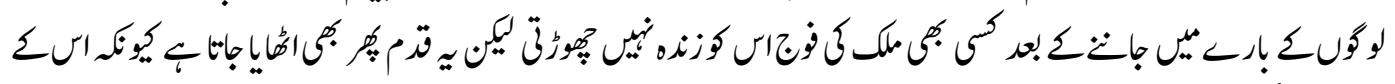

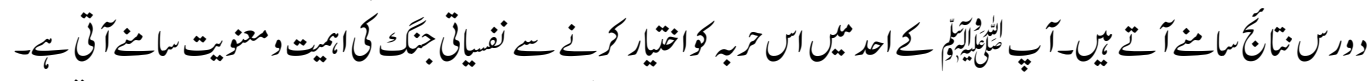

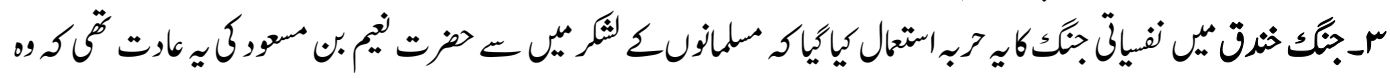

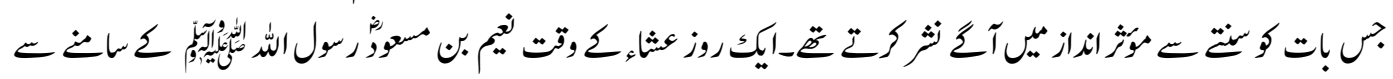

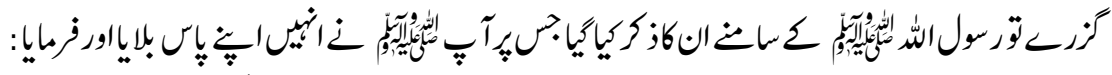

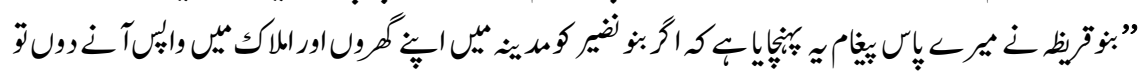

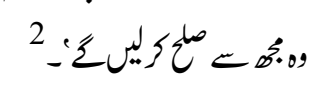

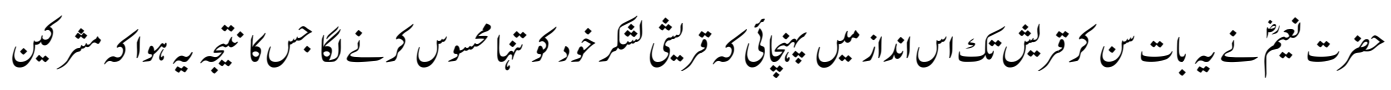

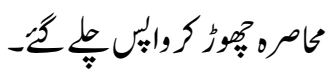

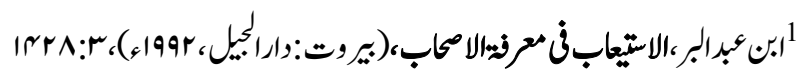

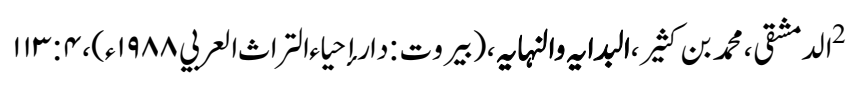




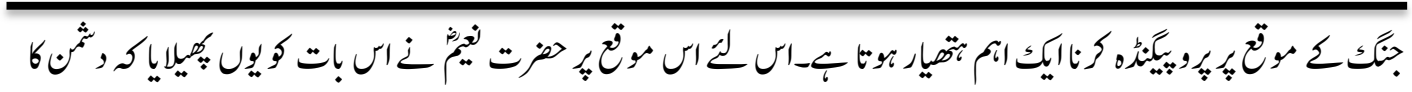

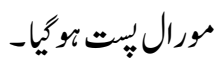

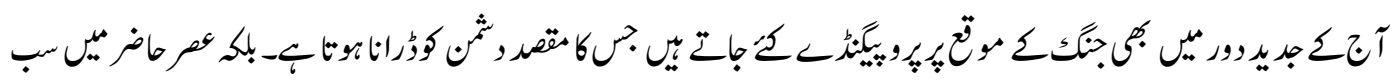

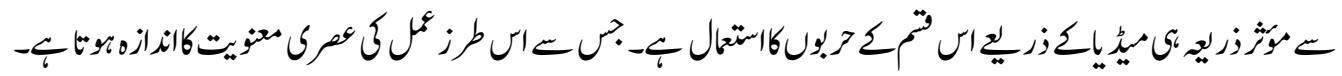

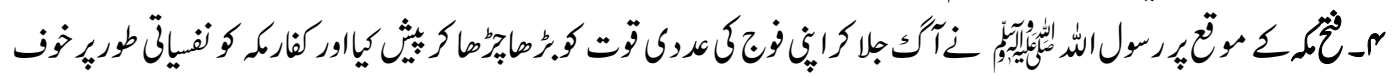

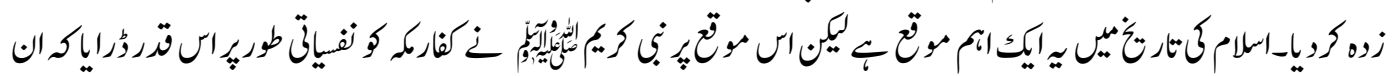

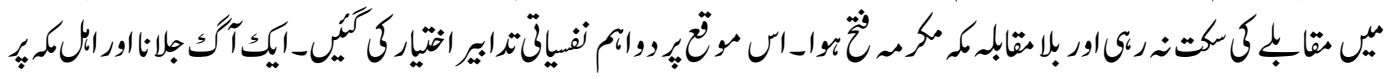

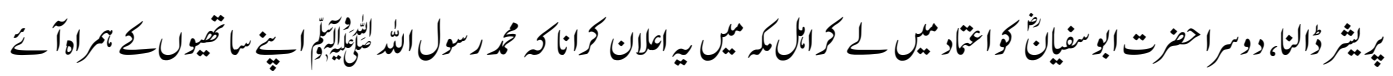

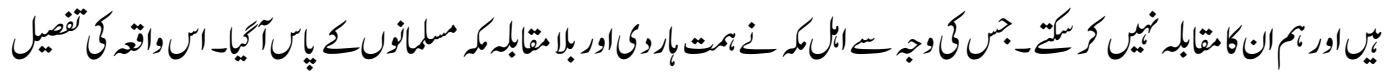

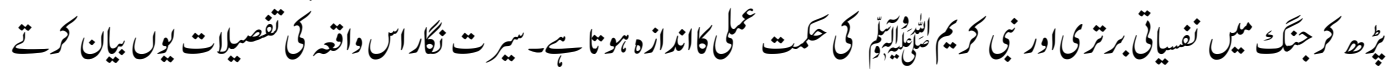

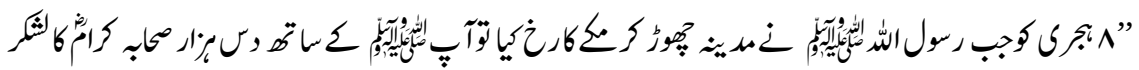

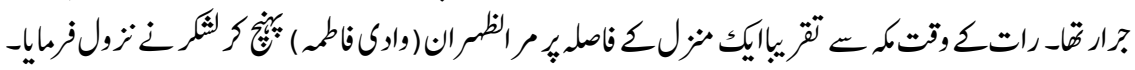

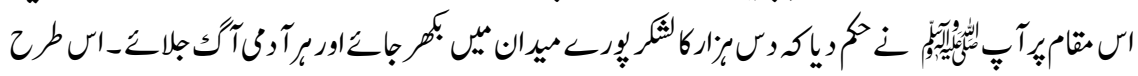

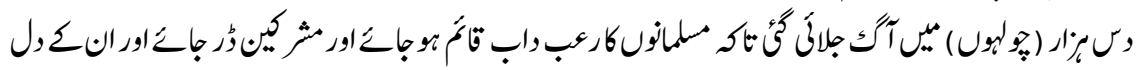

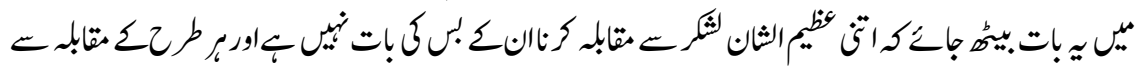

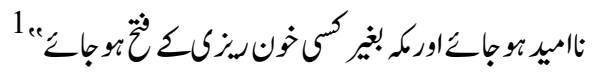

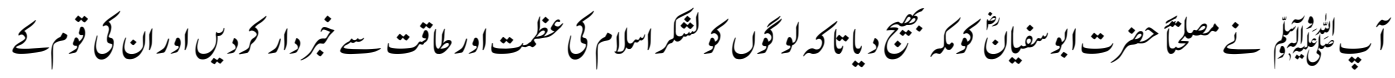

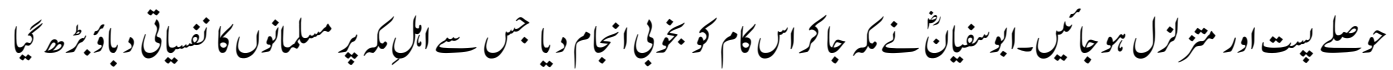

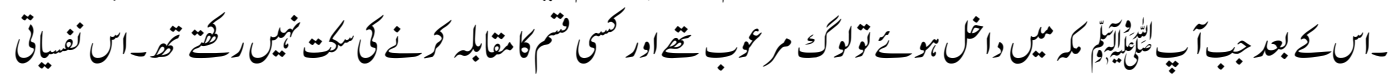

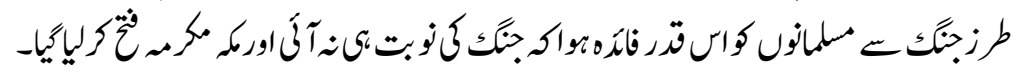

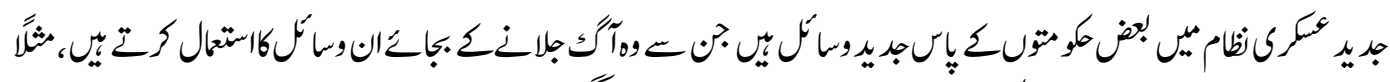

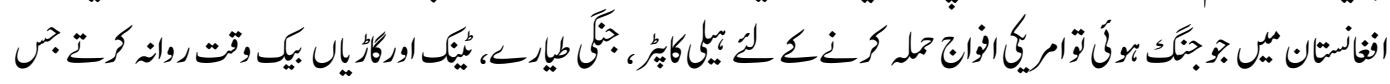

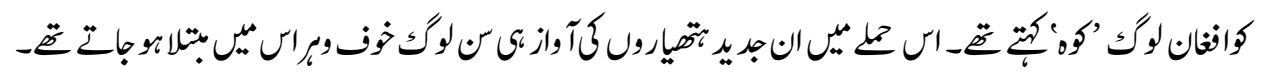

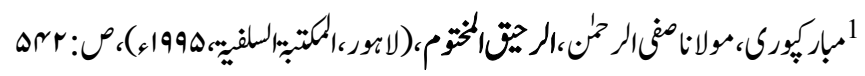




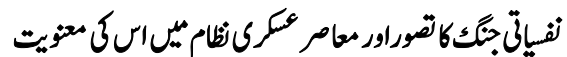

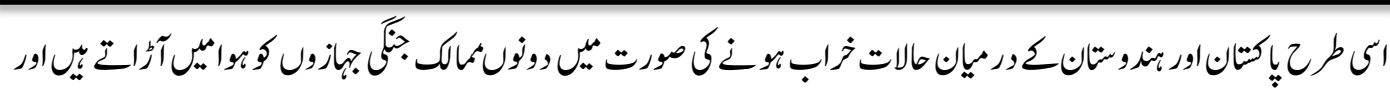

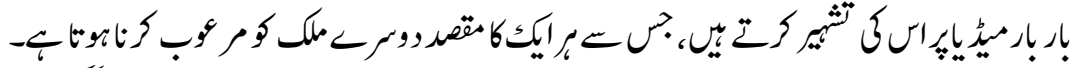

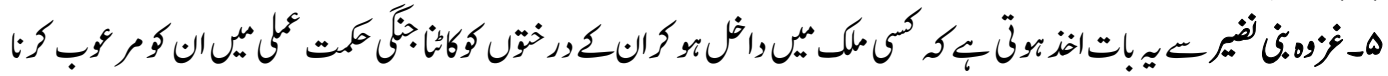

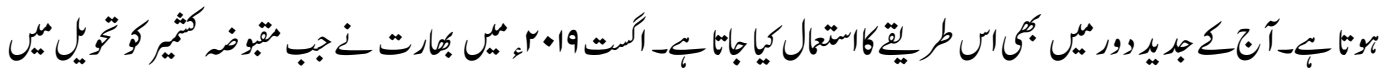

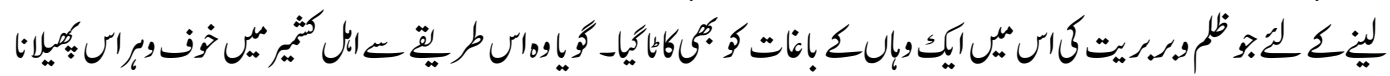

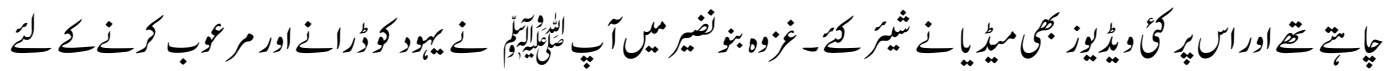

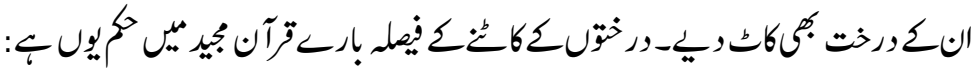

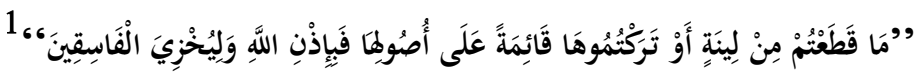

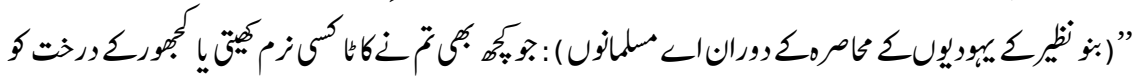

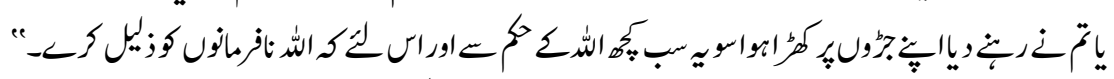

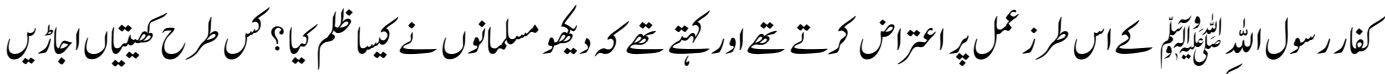

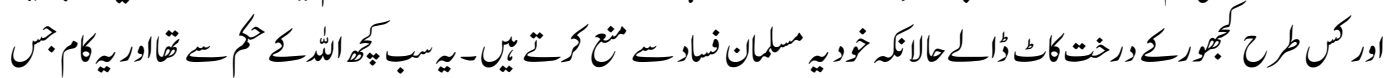

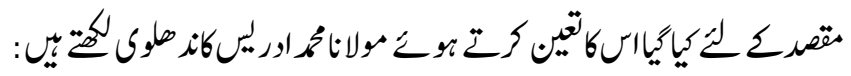

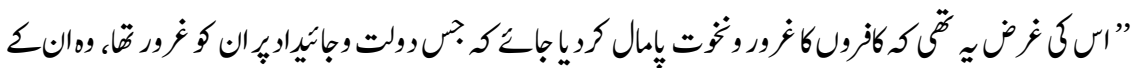

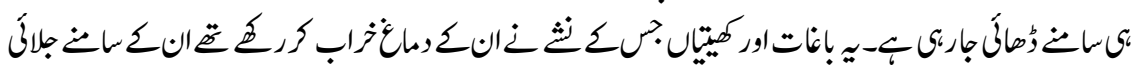

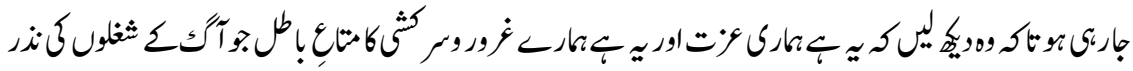
$2 " ب$ "

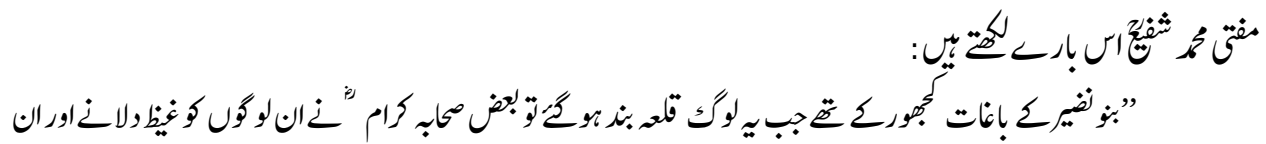

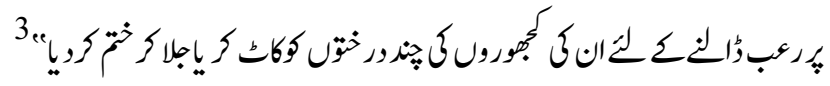

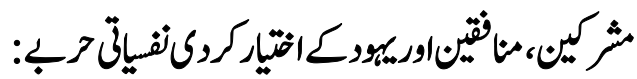

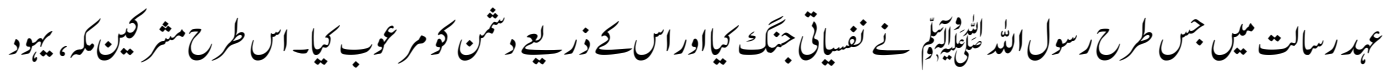

$$
\text { ه: }
$$

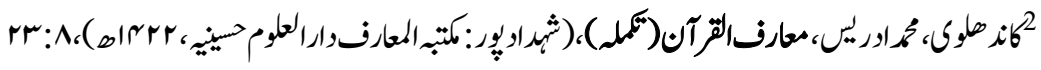

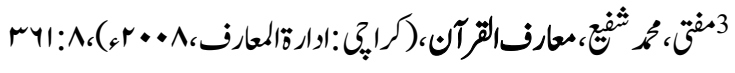


ايقّان: جلد: 02،ثراه:03،وكمبر2019؛

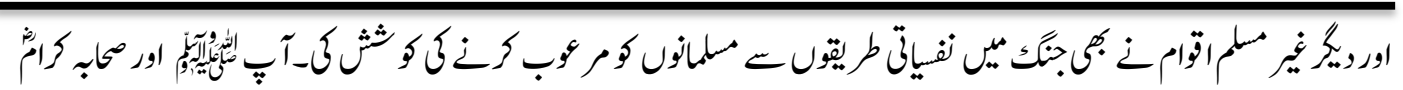

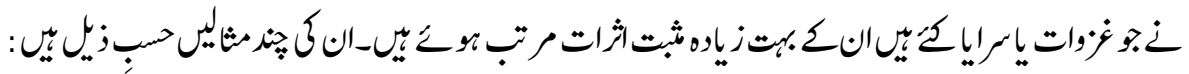

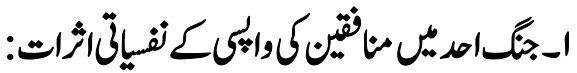

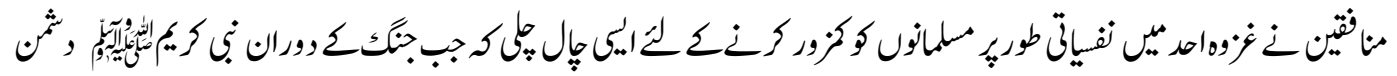

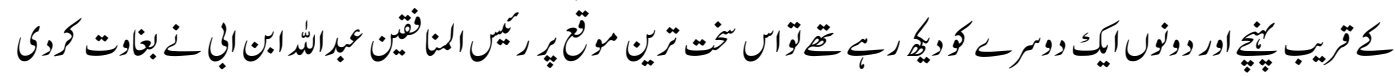

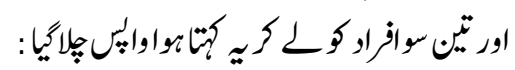

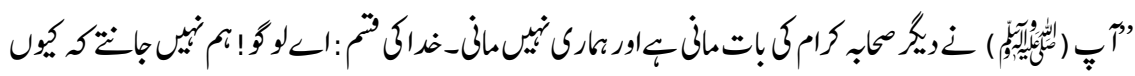

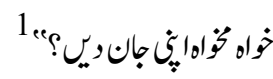

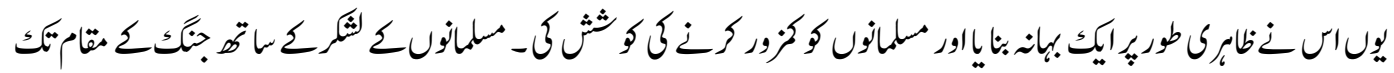

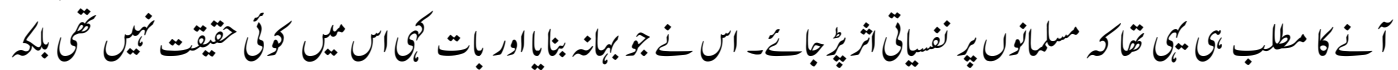

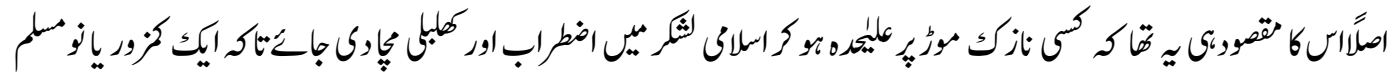

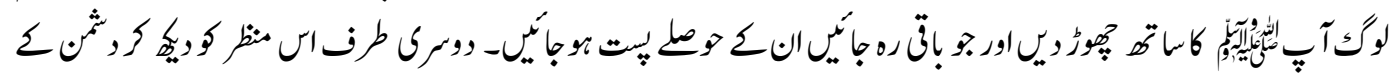

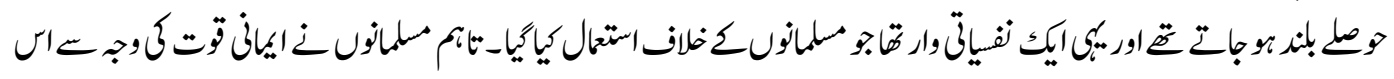

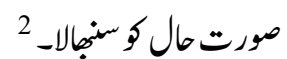

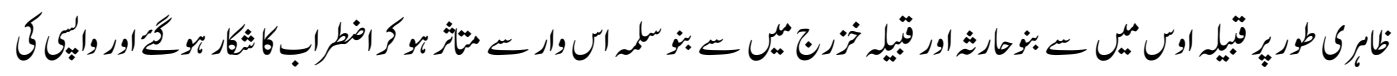

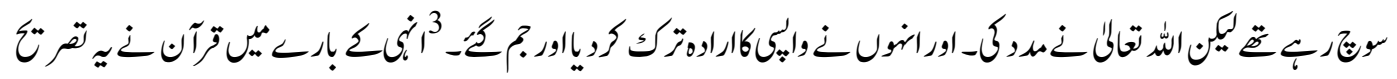

كَب:

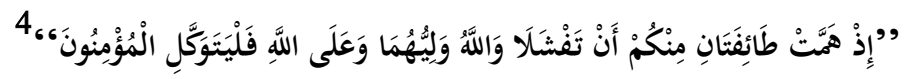

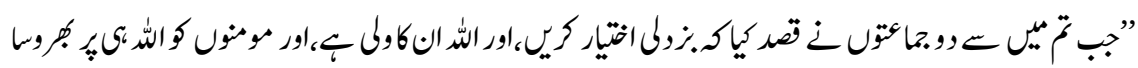

"ب⿱艹

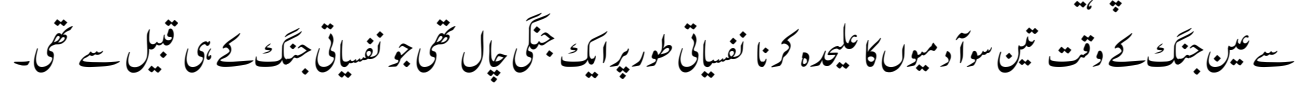

1

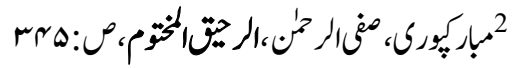

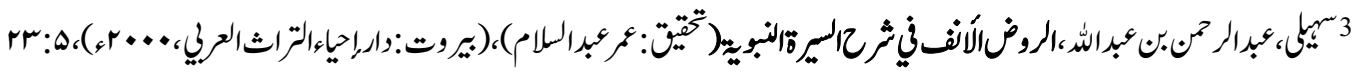

14:0

65 


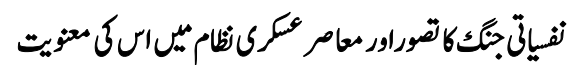
r

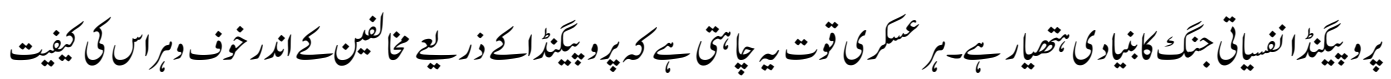

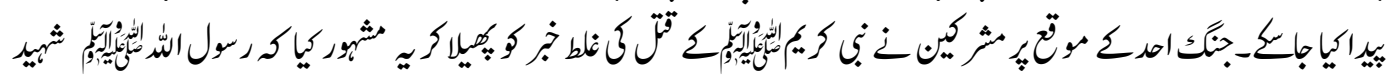

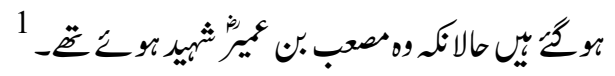

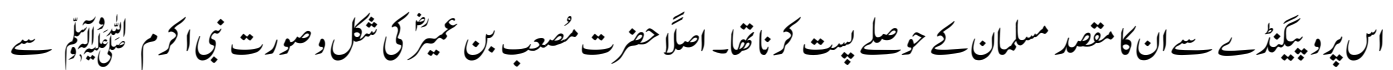

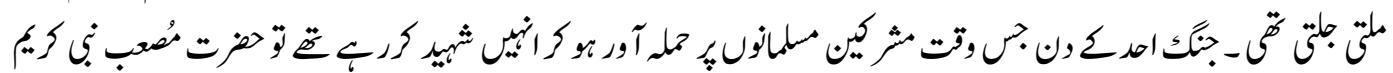

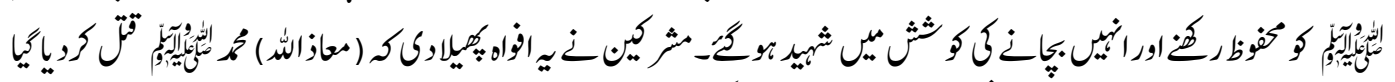

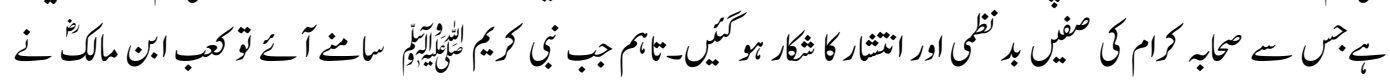

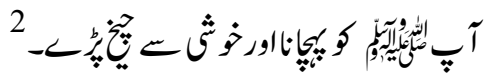

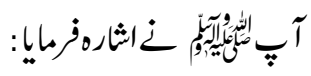

$$
\begin{aligned}
& \text { "أن اصمت" }
\end{aligned}
$$

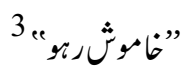

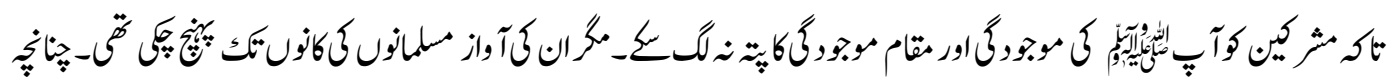

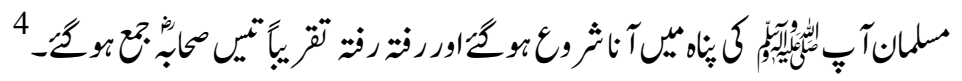

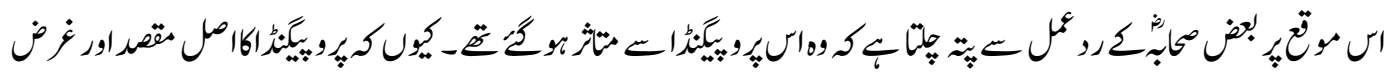

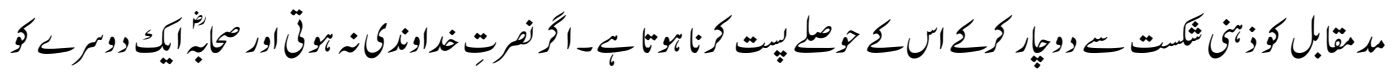

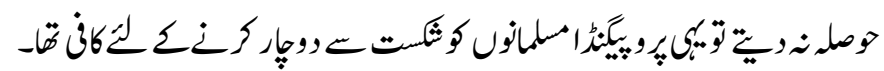

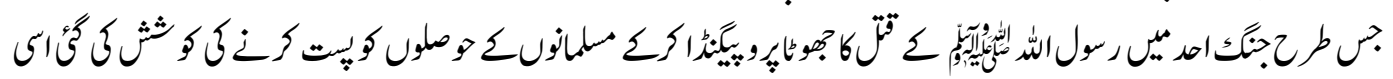

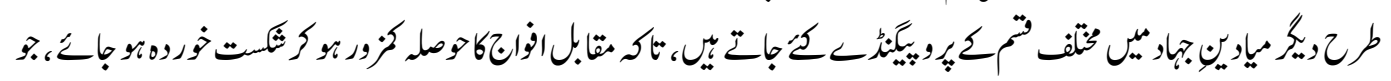

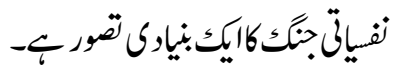

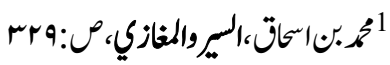

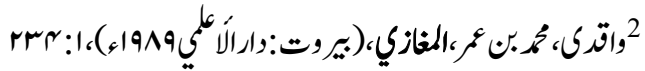

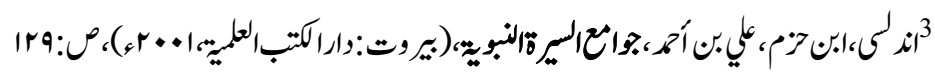

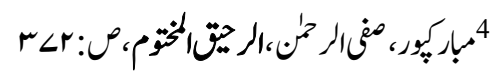




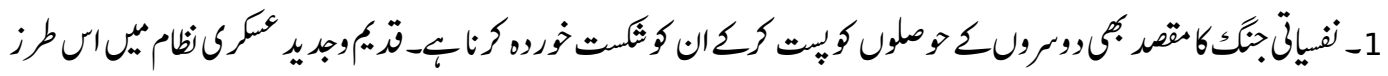

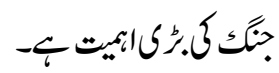

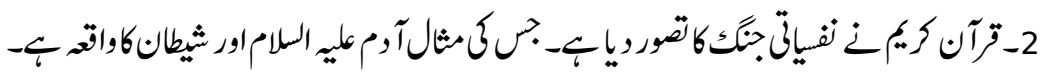

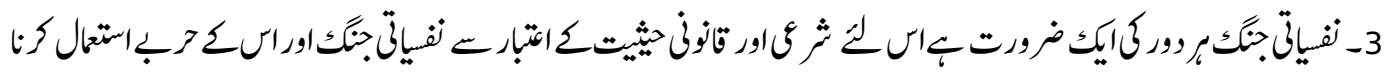

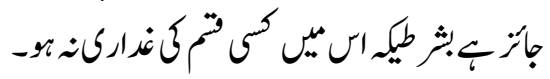

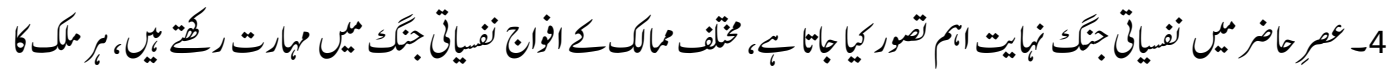

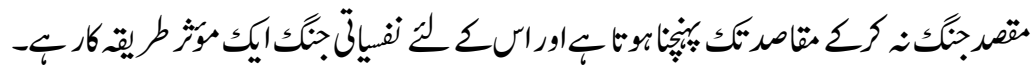

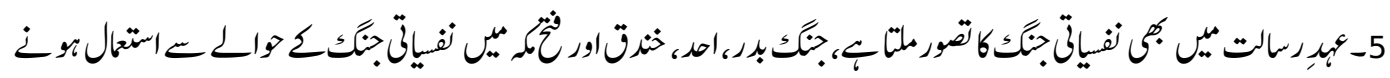

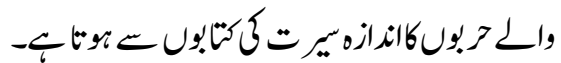

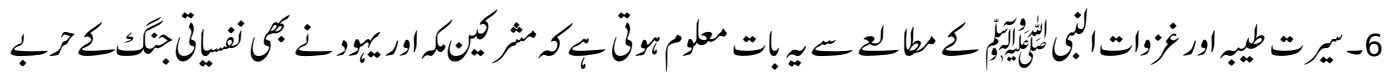

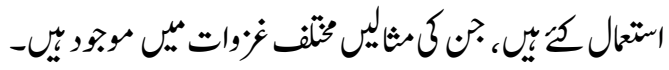

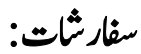

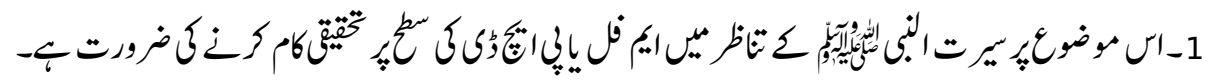

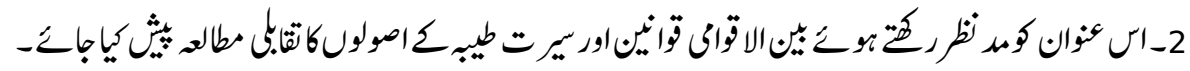

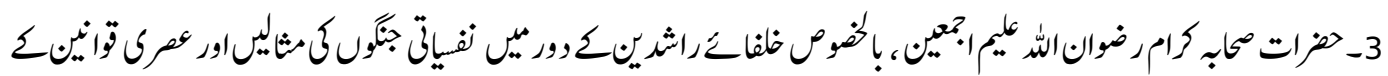

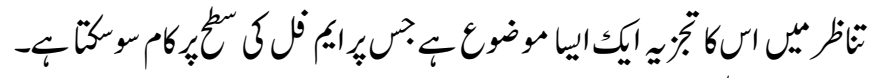

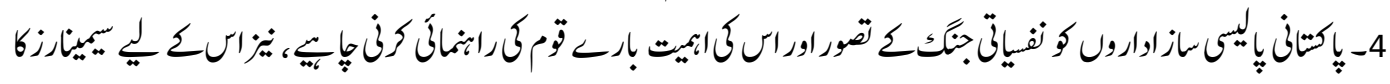

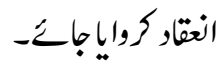

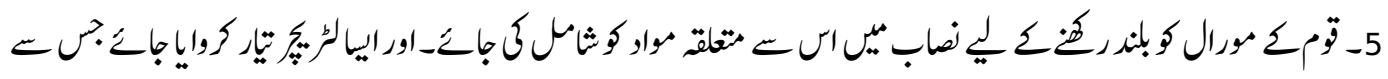

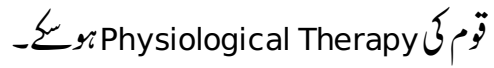

(a) 2019 by the author, this article is an open access article distributed Under the terms and conditions of the Creative Commons Attribution (CC BY) (http://creativecommons.org/licenses/by/4.0/) 